Esta revista forma parte del acervo de la Biblioteca Jurídica Virtual del Instituto de Investigaciones Jurídicas de la UNAM

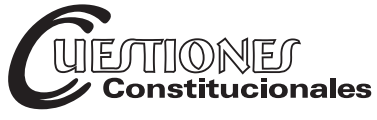

Revista Mexicana de Derecho Constitucional Núm. 44, Enero-Junio 2021

ISSN (versión electrónica): 2448-4881

\title{
Principio constitucional de la libre competencia
}

\section{Constitutional principle of free competition}

Recepción: 14 de enero de 2020

Aceptación: 6 de agosto de 2020

\author{
Vladimir RODRÍGUEZ CAIRO*
}

RESUMEN: La investigación examinó el contenido jurídico y económico de la libre competencia. El nivel del estudio fue descriptivo y la técnica de investigación la documentación. De este modo, se fundamentó la competencia como orden espontáneo y se analizó la trascendencia del principio constitucional de la libre competencia y su protección legal. El principal hallazgo del estudio es que, si bien el Tribunal Constitucional desarrolla el papel de los precios en la economía, no lo considera como elemento constitutivo de la libre competencia; tampoco a las ganancias libres. Se concluyó que, desde la incorporación del principio de la libre competencia en la Constitución económica peruana de 1993, existe un mandato expreso para que el Estado facilite la libre competencia contemplando sus cinco elementos constitutivos, y consiguientemente, vigile que no se cometan excesos ni se pon-
ABSTRACT: The investigation examined the legal and economic content of free competition. The level of the study was descriptive, and the research technique was documentation. In this way, competition was founded as a spontaneous order and the significance of the constitutional principle of free competition and its legal protection was analyzed. The main finding of the study is that, although the Constitutional Court develops the role of prices in the economy, it does not consider it as a constitutive element of free competition, neither to free earnings. It was concluded that, since the incorporation of the principle of free competition in the Peruvian economic Constitution of 1993, there is an express mandate for the State to facilitate free competition, contemplating its five constituent elements, and consequently, watch that excesses are not committed or put obstacles, and penalize abuses that are contrary to free competition.

* Profesor principal de la Universidad Nacional Mayor de San Marcos (UNMSM). Perú. Doctor en derecho y ciencia política por la UNMSM. Correo electrónico: vrodriguezc@unmsm.edu.pe ORCID: 0000-0001-9971-0405. 
Esta revista forma parte del acervo de la Biblioteca Jurídica Virtual del Instituto de Investigaciones Jurídicas de la UNAM

gan trabas, y se sancionen los abusos que sean contrarios a la libre competencia.

Palabras clave: libre competencia; orden espontáneo; principio del régimen económico constitucional; bienestar.
Keywords: free competition; spontaneous order; principle of the constitutional economic regime; welfare.

SUMARIO: I. Introducción. II. Fundamentación de la libre competencia. III. Antecedentes de la libre competencia en las constituciones peruanas del siglo XX. IV. Positivización del principio de la libre competencia en la Constitución económica peruana de 1993. V. Interpretación del principio de la libre competencia según el Tribunal Constitucional peruano. VI. Falla de la competencia, poder de mercado y protección legal de la libre competencia. VII. Conclusiones. VIII. Fuentes consultadas.

\section{INTRODUCCIÓN}

El principio de la libre competencia forma parte del conjunto de normas constitucionales principio que orientan el modelo económico constitucional peruano y, por tanto, la vida económica del país. "Las normas constitucionales principio tienen una aplicación generalizada y permanente en todo el derecho del Estado" (Rubio, 2013, p. 58). De manera que, la libre competencia es una norma constitucional principio que constituye el criterio orientador para que la competencia opere de la manera más beneficiosa posible y permita lograr el bienestar de los que participan en un intercambio.

Ahora bien, la Constitución económica peruana dispone que el Estado facilita y vigila la libre competencia. Es así que la libre competencia es uno de los principios generales del régimen económico constitucional peruano. En ese sentido, desde su incorporación expresa en 1993, la libre competencia ha contribuido al buen funcionamiento de los mercados. Siendo así, al ser uno los principios fundamentales de una economía de mercado, se basa en la libre concurrencia de la oferta y la demanda, la actuación libre dentro del mercado, el sistema de precios libres y las ga- 
Esta revista forma parte del acervo de la Biblioteca Jurídica Virtual del Instituto de Investigaciones Jurídicas de la UNAM

nancias también determinadas libremente, esto es, productores y consumidores concurren al mercado en igualdad de condiciones, de tal manera que los más eficientes tienen la posibilidad de hacer mejores intercambios en el mercado. Razón por la cual, el Estado debe orientar sus esfuerzos para lograr un mejor funcionamiento de los mercados evitando que se cometan excesos y se pongan trabas a la libre competencia.

Cabe precisar que uno de los grandes aportes de Hayek, fue sin lugar a duda, su teoría sobre la autogeneración de diversos órdenes espontáneos, como el trueque, el mercado, la competencia, la sociedad, entre otros. En efecto, fue el pionero en la elaboración de una teoría del orden espontáneo de la competencia. Para él, la competencia es un proceso de descubrimiento a través del cual el sistema de precios sólo cumplirá su función si prevalece la libre competencia. En ese sentido, la competencia constituye un orden espontáneo que se caracteriza porque los individuos pueden elegir libremente, dentro de ciertos límites, los medios y los fines de sus actividades. En esa misma línea, Kirzner sostiene que la competencia es un proceso activo y no una situación exenta de actividad competitiva.

Así, para Rothbard (2013: 157), “en el mundo de la producción, el mercado libre puede calificarse como de libre competencia o entrada, para significar que en una sociedad libre todo el mundo tiene libertad para competir y producir en cualquier terreno que elija". Además, "la libre competencia es la aplicación de la libertad al ámbito de la producción: libertad de comprar, vender y transformar los propios bienes sin intromisión violenta de ningún poder externo". Desde tal perspectiva, "la expresión libre competencia resultará, pues, equívoca a menos que se interprete como que significa libertad de acción, es decir, libertad para competir o no competir, según sea la voluntad de los individuos" (Rothbard (2013: 158 y 159).

Definitivamente, "la regla general será que los agentes del mercado actúen en el marco constitucional de libre competencia; sin embargo, existirán supuestos en los cuales el Estado deberá intervenir mediante la regulación para corregir determinadas fallas de mercado" (Tassano, 2016: 108). Desde luego, la protección constitucional de la libre competencia, así como las normas de menor jerarquía o una combinación de ambas, son formas de intervención estatal en los diversos mercados orientadas a corregir la falla de la competencia, vinculada a los tipos de imperfección del mercado: monopolio, oligopolio, competencia monopolística, monopsonio, oligopsonio. 
Esta revista forma parte del acervo de la Biblioteca Jurídica Virtual del Instituto de Investigaciones Jurídicas de la UNAM

Dentro de este contexto, el estudio busca responder a la siguiente interrogante: ¿Cuál es el contenido jurídico y económico del principio constitucional de la libre competencia? Así, el objetivo de la presente investigación fue examinar el contenido jurídico y económico del principio constitucional de la libre competencia.

\section{FUNDAMENTACIÓN DE LA LIBRE COMPETENCIA}

\section{Competencia como orden espontáneo}

La competencia es un proceso mediante el cual se despliega la rivalidad o contienda entre dos o más individuos que buscan un fin específico, producto de las acciones humanas que individualmente implica optar y procurar alcanzar un fin (revertir el estado de necesidad o insatisfacción). En el proceso de la competencia, la rivalidad se presenta fundamentalmente entre las empresas cuando tratan de captar clientes o entre los consumidores cuando desean adquirir bienes y/o servicios.

La libre competencia entre los individuos es la institución reguladora del mercado. Es así que, "al orientar esa actividad de manera de producir un valor máximo él (individuo) busca sólo su propio beneficio, pero en este caso como en otros una mano invisible lo conduce a promover un objetivo que no entraba en sus propósitos" (Smith, 2011: 554). Del mismo modo, contempla que entre las legítimas tareas del gobierno estaba el de lograr abundancia y abaratamiento, promoviendo la mayor competencia posible en todos los mercados.

Bajo el enfoque de Hayek, la competencia es considerada como un procedimiento para descubrir hechos que, de no recurrir a ella, serían desconocidos para todos o, por lo menos, no serían utilizados.

Baste esto para indicar a qué clase de conocimiento me refiero cuando califico a la competencia como "un método de descubrimiento". Se podrían añadir aún muchas cosas para revestir esta descarnada afirmación en orden a mostrar toda su importancia práctica. Pero debo contentarme con aludir brevemente a lo absurdo del procedimiento habitual consistente en iniciar el análisis con una situación en la que se supone que todos los hechos son conocidos. Es esta una situación que la teoría económica llama curiosamente "competencia 
Esta revista forma parte del acervo de la Biblioteca Jurídica Virtual del Instituto de Investigaciones Jurídicas de la UNAM

perfecta". No deja espacio alguno a la actividad llamada competencia, que se supone ha cumplido ya su tarea (Hayek, 2015: 231).

Esto quiere decir que, la competencia es un proceso de descubrimiento que proviene de las acciones humanas individuales, y como tal, se basa en un orden espontáneo que se descubre o autogenera a través del ensayo y el error. Mediante este proceso los individuos pueden elegir libremente, dentro de ciertos límites, los medios y los fines de sus actividades. Es un proceso que nadie controla — que carece de finalidad concreta - y cuyo resultado en gran parte es imprevisible.

Debe enfatizarse que, este proceso de descubrimiento implica que las empresas rivalizan entre sí por captar más clientes, y al hacerlo tratan de ofrecer los bienes y/o servicios que éstos desean al menor precio posible. De igual manera, los consumidores también contienden entre ellos mismos por disponer de los bienes y/o servicios que son ofrecidos a un precio determinado. Por ello, la interacción entre ofertantes y demandantes determina el precio de mercado.

Igualmente, "la competencia hay que enfocarla como un proceso a través del cual la gente adquiere y transmite conocimiento" (Hayek, 2014, p. 436). Por tanto:

La competencia, si no se la obstaculiza, tiende a crear una situación en la que, en primer lugar, se producirá todo bien que se desea producir y vender provechosamente a un precio que los consumidores prefieren a otras alternativas disponibles; en segundo lugar, todo bien será producido por individuos que saben producirlo por lo menos tan económicamente como los que no se ponen a producirlo; en tercer lugar, todo se venderá a precios inferiores o a lo sumo iguales a aquellos a los que lo venderían quienes de hecho no se han puesto a venderlo (Hayek, 2014: 411).

\section{Competencia y dimensiones del mercado}

La competencia es un proceso que se desarrolla en el mercado, el cual se concibe, no necesariamente como el lugar que permite interconectar a ofertantes y demandantes, sino a la relación de intercambio entre un oferente y un demandante de bienes o servicios. Según Kirzner, "una comprensión útil de los procesos del mercado requiere una noción de competencia analíticamente inseparable de la función empresarial". De este 
Esta revista forma parte del acervo de la Biblioteca Jurídica Virtual del Instituto de Investigaciones Jurídicas de la UNAM

modo, asevera que "el mercado, es el resultado de las decisiones recíprocas de los consumidores, empresarios y propietarios de los recursos" (Kirzner, 1998: 24 y 25).

En esa línea, para Mises intercambiar es actuar, por lo que, dentro del intercambio en el mercado, considera a la competencia como la oportunidad para ofrecer a los consumidores a un precio más barato posible.

Dentro de este marco, todo intercambio tiene una doble dimensión: la económica y la jurídica. La dimensión económica consiste esencialmente en la transmisión de la mercancía y la dimensión jurídica implica la transmisión del derecho de propiedad (figura 1).

\section{FIGURA 1. MERCADO: RELACIÓN DE INTERCAMBIO \\ ENTRE OFERTANTE Y DEMANDANTE.}

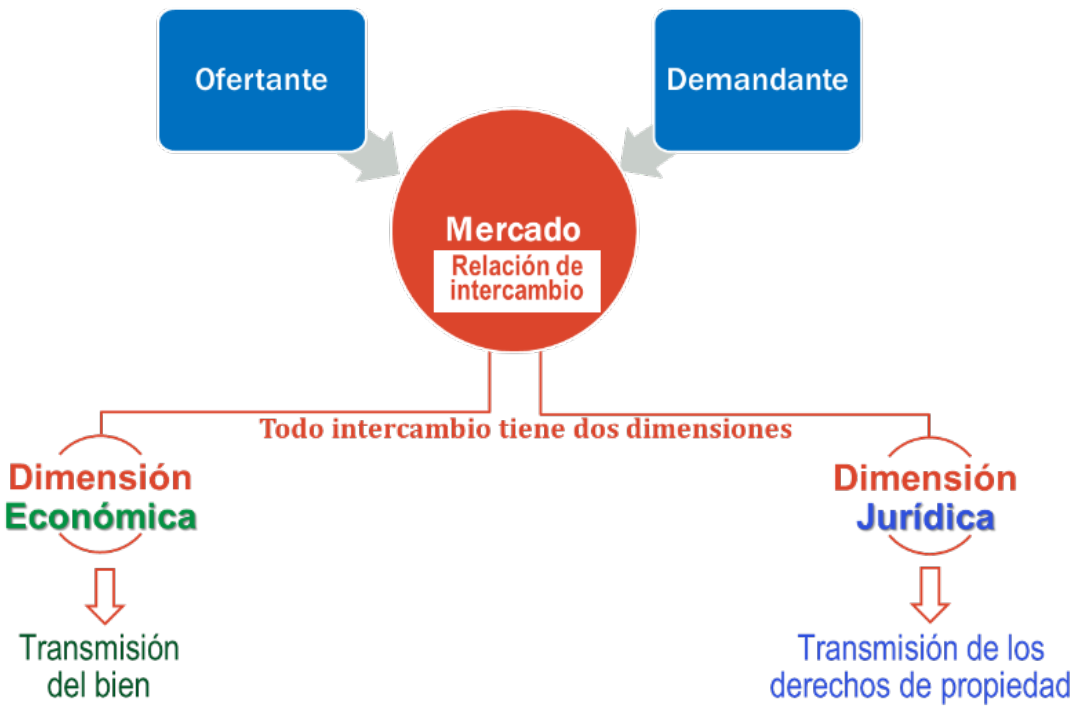

FUENTE: Elaboración propia.

Precisamente, la dimensión económica del mercado implica la competencia entre los participantes, sean estos, consumidores o productores.

La competencia cataláctica - nota característica de la economía de mercado- es un fenómeno social. No implica derecho alguno, garantizado por el 
Esta revista forma parte del acervo de la Biblioteca Jurídica Virtual del Instituto de Investigaciones Jurídicas de la UNAM

Estado y las leyes, que posibilite a cada individuo elegir ad libitum (a voluntad) el puesto que más le agrada en la estructura de la división del trabajo... $\mathrm{El}$ acceso a una determinada rama industrial virtualmente es libre, pero sólo se accede a la misma si los consumidores desean que sea ampliada la producción en cuestión o si los nuevos industriales son capaces de desplazar a los antiguos satisfaciendo de un modo mejor o más económico los deseos de los consumidores (Mises, 2011: 334).

A su vez, la dimensión jurídica del mercado consiste en un conjunto de reglas de juego que permiten que los potenciales ofertantes y demandantes intercambien un producto. Tales reglas de juego están referidas fundamentalmente a los derechos de propiedad de las personas sobre los bienes. Esto permite un adecuado funcionamiento de los mercados, logrando un intercambio más eficiente. En definitiva, "para el funcionamiento de los mercados se requiere de normas legales que establezcan claramente los derechos y deberes de aquellos que llevan a cabo transacciones" (Coase, 1988: 16).

\section{Contenido de la libre competencia}

La competencia, al ser un proceso de descubrimiento, disciplina a numerosos productores y consumidores a ajustar su estilo de vida de un modo que ninguna ley lograría hacerlo. Los elementos constitutivos de la libre competencia, tanto por el lado de la oferta como por el lado de la demanda, son: "la concurrencia libre al mercado, los precios y las ganancias libres" (Boloña, 1995: 42). A ello habría que añadir la libre iniciativa o actuación dentro del mercado, así como la igualdad de los competidores ante la ley. En la siguiente figura, se presentan los cinco elementos constitutivos de la libre competencia. 
Esta revista forma parte del acervo de la Biblioteca Jurídica Virtual del Instituto de Investigaciones Jurídicas de la UNAM

\section{FIGURA 2. ELEMENTOS CONSTITUTIVOS}

DE LA LIBRE COMPETENCIA

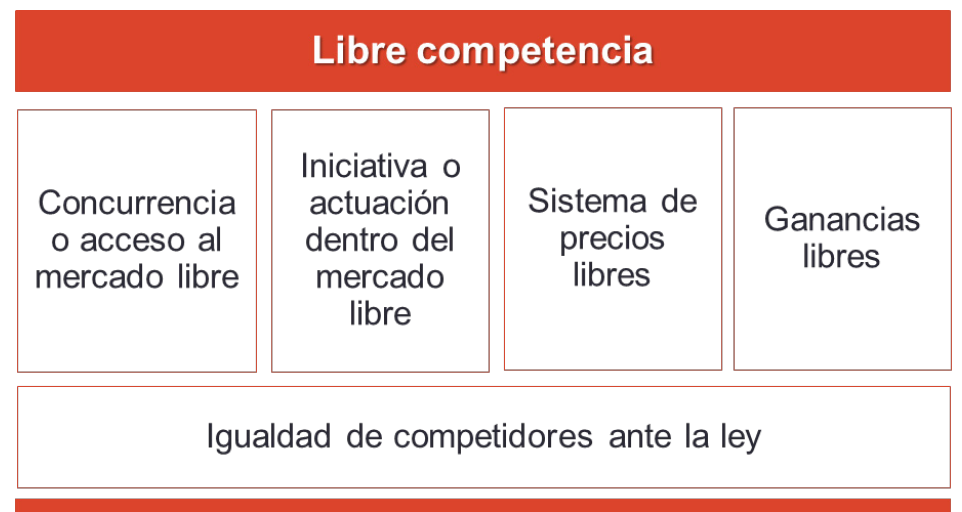

FUENTE: Elaboración propia.

La concurrencia libre al mercado implica que quienes tienen la capacidad y voluntad de ofrecer o demandar un producto, puedan acceder al mercado de manera libre, sin que exista un tercero, generalmente el Estado, que restrinja, limite o prohíba dicha participación. La libre actuación dentro del mercado implica que luego que los ofertantes y demandantes hayan accedido al mercado, puedan de manera libre continuar compitiendo. Queda claro que, tanto en la libre concurrencia como en la libre actuación en el mercado, debe primar la igualdad ante la ley y las ganancias que se obtengan de esa interacción también deben ser libres. El verdadero soporte de la libre competencia es la igualdad ante la ley o más específicamente la libertad de oportunidades entre los competidores.

En línea con lo sostenido por Hayek, la verdadera función del sistema de precios es considerar dicho sistema como un mecanismo que permite comunicar información. Por tanto, el sistema de precios libres es un orden espontáneo generado de manera evolutiva como resultado de acciones humanas individuales, y, por tanto, no es producto del diseño humano. Es un mecanismo que permite detectar y transmitir información económica que se encuentra dispersa entre una gran cantidad de personas. 
Esta revista forma parte del acervo de la Biblioteca Jurídica Virtual del Instituto de Investigaciones Jurídicas de la UNAM

Si los precios son relativamente altos habrá una demanda insatisfecha y, por tanto, una oportunidad para obtener mayores ganancias. Si el acceso al mercado es libre, las mayores ganancias relativas atraerán la inversión de mayor capital, con lo cual la oferta aumentará, los precios empezarán a bajar y las ganancias unitarias tenderán a normalizarse. De ahí que la libre competencia es el mecanismo más efectivo para promover la asignación eficiente de los recursos en el mercado.

En ese orden de ideas, "a través del sistema de precios, los individuos cooperan pacíficamente durante breves momentos, mientras que durante el resto del tiempo cada cual se ocupa de sus propios asuntos" (Friedman y Friedman, 1980: 31).

De esta forma, el sistema de precios libres permite que tanto productores como consumidores expresen su voluntad de manera libre respecto del precio de un bien, así como las necesidades que desean satisfacer. Por ello, el sistema de precios libres es el mecanismo más efectivo para generar bienestar a los consumidores. De ello se colige que el Estado debe establecer mecanismos de protección legal para garantizar la libre competencia y con ello, preservar un sistema de precios libres. Debe reconocerse también que los precios cumplen dos funciones esenciales en la organización de la actividad económica: 1) transmiten información entre los que participan en el mercado; 2) proveen incentivos para adoptar decisiones sobre el consumo de un bien, así como los métodos de producción menos costosos.

\section{Libre competencia y bienestar}

Como argumenta Menger, "El principio que induce a los hombres al intercambio es aquel que guía toda su actividad económica en general, esto es, el deseo de satisfacer sus necesidades de la manera más perfecta posible" (Menger, 2013: 240). Dentro de este contexto, si el problema económico de fondo es la escasez, entonces de los siguientes dos escenarios (figura 3), el escenario 1 es el que permite reducir la escasez: la libre competencia.

Dentro del marco del escenario 1, en última instancia, se termina beneficiando a los consumidores, ya que el hecho de velar por la libre competencia contribuye a generar una mayor competencia por parte de las empresas, que se traduce en una mayor oferta, y, por tanto, tiende a disminuir el precio y aumentar el consumo, con lo cual existe menor escasez; 
Esta revista forma parte del acervo de la Biblioteca Jurídica Virtual del Instituto de Investigaciones Jurídicas de la UNAM

consiguientemente, habrá mayor bienestar para los consumidores. Efectivamente, si en el presente existe un mayor consumo, nuestro nivel de bienestar aumenta. Esta es la gran ventaja de la libre competencia: por el lado de la oferta eleva el bienestar de los consumidores. De manera similar, si en el presente existe un mayor ahorro y la intención es postergar el consumo para el futuro, en ese momento futuro, el nivel de bienestar del consumidor será mayor.

\section{FIGURA 3. ESCENARIOS DE LA COMPETENCIA POR EL LADO DE LA OFERTA.}

Escenario 1

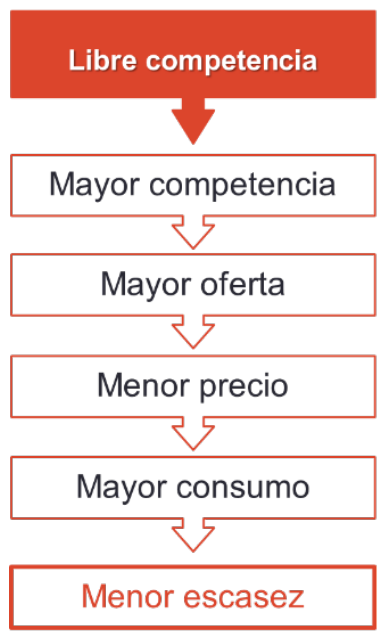

Escenario 2

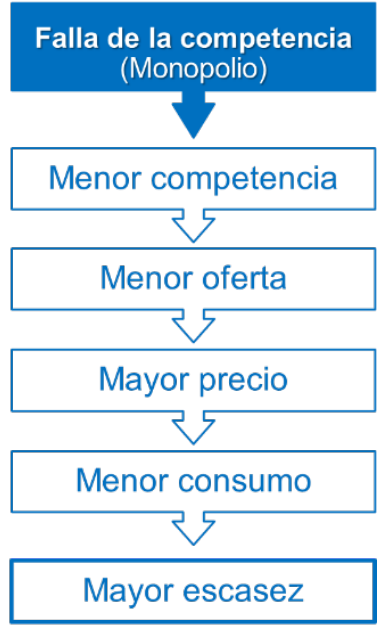

FUENTE: Elaboración propia.

De lo anterior se desprende que el escenario 1 es el más adecuado, que consiste en promover mayor competencia, no sólo para los consumidores sino también para los productores, porque esta es la vía que obliga a los productores a ser más productivos y competitivos, mediante los cuales los precios tienden a ser menores.

Ahora bien, resulta pertinente formular la siguiente interrogante: ¿Cómo se logra facilitar la libre competencia en el mercado? En general, cuando el gobierno no constriñe la libertad de elegir de los individuos en el mercado, es decir, cuando permite que toda persona sin distinción sea nacional o Cuestiones Constitucionales, Núm. 44, Enero-Junio 2021 ISSN: 2448-4881 
Esta revista forma parte del acervo de la Biblioteca Jurídica Virtual del Instituto de Investigaciones Jurídicas de la UNAM

extranjera, que decida participar en las actividades económicas del país lo pueda realizar sin ningún obstáculo o restricción gubernamental. Razón por la cual, el Estado debe vigilar la libre competencia, que los ofertantes de bienes y servicios no se pongan de acuerdo para llevar a cabo conductas anticompetitivas como la concertación de precios o prácticas restrictivas. De ahí que resulta relevante la intervención del aparato estatal para garantizar la libre competencia en los diversos mercados.

En definitiva, donde hay más competencia, los ofertantes de bienes y servicios necesariamente tendrán que hacer un uso más económico de los factores de la producción que tienen a su disposición, porque la competencia se configura como una amenaza para salir del mercado.

\section{Libre competencia, productividad, competitividad y precios}

El primer paso para economizar por el lado de la oferta (minimizar en lo posible el problema de la escasez) es la mayor productividad y el único incentivo para que las empresas se vuelvan más productivas es la libre competencia. Desde tal perspectiva, "un proceso competitivo avanza porque los participantes están comprometidos en la carrera incesante para ponerse o mantenerse a la cabeza de los demás... el empresario nunca puede ser inmune a la presión competitiva" (Kirzner, 1998: 35).

En efecto, la libre competencia promueve mayor productividad, ${ }^{1}$ lo que se traduce en mayor competitividad ${ }^{2}$ dentro del mercado, y una mayor competitividad, se refleja en menores precios. En la siguiente figura, se puede observar que, a mayor productividad, mayor será la competitividad y menores los precios.

1 La productividad es el rendimiento que se obtiene de cada factor de producción o, dicho de otra forma, es la capacidad de hacer más con menos recursos.

2 La competitividad se refiere a la capacidad de competir o capacidad que tienen los diversos agentes económicos que participan en un mercado de bienes y servicios internos o externos, de obtener mejores resultados que el resto de los agentes con los que compite. 
Esta revista forma parte del acervo de la Biblioteca Jurídica Virtual del Instituto de Investigaciones Jurídicas de la UNAM

\section{FIGURA 4. LIBRE COMPETENCIA Y MENORES PRECIOS.}

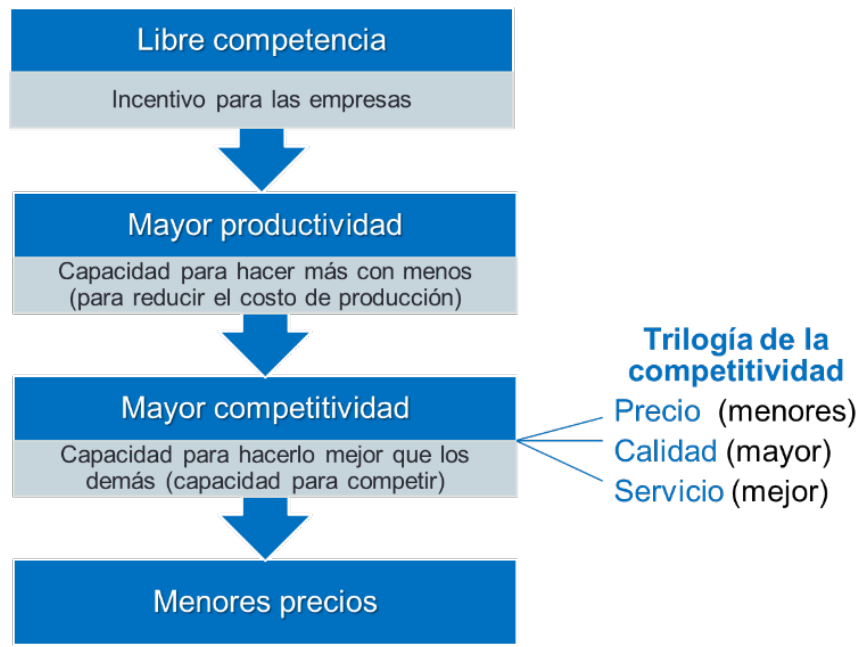

FUENTE: Elaboración propia.

Como se sabe, la productividad y la competitividad son barreras naturales no artificiales que impiden entrar a un mercado, y, por lo tanto, son las que en cierta forma se justifican en la práctica. Sin embargo, una barrera artificial también se da cuando el gobierno prohíbe que alguien más participe en un mercado específico. Con bastante frecuencia, el argumento utilizado para que el gobierno les proteja de la competencia, sobre todo del exterior, viene a ser la supuesta afectación del nivel de empleo.

Contrario a ello, la mayor competencia, en cierta forma, origina que se pierdan empleos poco productivos, porque se libera la mano de obra que tendrá que emplearse en trabajos más productivos, y eso es economía (asignación eficiente de recursos escasos). Por tal razón, se debe tomar en cuenta que, en reiteradas ocasiones, de manera errónea, se responsabiliza a los extranjeros de la pérdida de empleo de los trabajadores nacionales.

Si bien a todas las empresas les resulta conveniente el monopolio (porque no hay amenaza), la mayor competencia los obliga a ser más productivos en el uso de los factores de la producción, permitiéndoles ser más competitivos sobre todo vía precios. De esta forma, la rivalidad entre las empresas tiende a disminuir los precios de los bienes y servicios en los 
Esta revista forma parte del acervo de la Biblioteca Jurídica Virtual del Instituto de Investigaciones Jurídicas de la UNAM

diversos mercados; por lo que, el resultado final de dicha competencia es el menor precio pagado por los consumidores.

\section{Derechos y obligaciones en el intercambio en el mercado}

Existen dos posiciones opuestas entre ofertante y demandante: el consumidor tiene el interés de comprar al menor precio posible y el productor desea vender al mayor precio. De manera que, para comprender la relación entre ofertantes y demandantes, cabe plantear la siguiente interrogante: ¿El consumidor tiene derecho a que se le ofrezca un bien o servicio al menor precio posible? Definitivamente, el consumidor no tiene el derecho a que se le ofrezca un producto al menor precio posible, lo que debe primar es el interés que se le brinde ese producto al menor precio posible, para lo cual es necesario que el Estado a través de la regulación, vele por la libre competencia y proteja la libertad de elegir de los participantes en los intercambios en el mercado.

De igual forma, se debe buscar responder otra pregunta: ¿El consumidor tiene derecho de comprar lo que desee? La respuesta es afirmativa. Este es el derecho a la libertad de elegir, esto es, la libertad individual para consumir. No obstante, si el consumidor tiene ese derecho, ¿Cuál es la obligación? El Estado tiene la obligación de no limitar esa libertad, por ejemplo, prohibiendo importaciones, lo cual daría como resultado menor competencia en el mercado, lo que implicaría que nos encontremos en el escenario 2: falla de la competencia, tal como se representó en la figura 3. Por ello, resulta vital legalizar la libertad, pero no para restringirla o vulnerarla, por el contrario, para garantizarla y facilitarla, como es el caso de la libre competencia. Entonces, queda claro que, para facilitar y vigilar la libre competencia, el Estado debe intervenir a efectos de corregir cualquier situación que la obstaculice.

La competencia de productos del exterior, siempre que no se trate de competencia desleal, lejos de ser perjudicial, resulta beneficiosa para el consumidor, ya que obliga al productor nacional a mantenerse permanentemente al día con la tecnología y a obtener productos cada vez de mejor calidad y a menores precios.

Como resulta evidente, ante la competencia extranjera, los productores nacionales muchas veces exigen al gobierno que se decida por el escenario dos (falla de la competencia), considerando que esta medida, tal vez 
Esta revista forma parte del acervo de la Biblioteca Jurídica Virtual del Instituto de Investigaciones Jurídicas de la UNAM

impida el desempleo (efecto inmediato), sin embargo, en el largo plazo, al haber menos competencia ocasionará: menor oferta, mayor precio, menor consumo, y consiguientemente, mayor escasez.

\section{ANTECEDENTES DE LA LIBRE COMPETENCIA EN LAS CONSTITUCIONES PERUANAS DEL SIGLO XX}

En el siglo XX, se promulgaron tres constituciones en el Perú en los años: 1920, 1933 y 1979. Al respecto, "Todas las constituciones peruanas del siglo XX fracasaron, en el propósito de dar estabilidad jurídica y sobre esta base, alentar el desarrollo económico y social" (Cháñame, 2009, p. 81).

Constitución de 1920. Esta Constitución incorpora el constitucionalismo social. Es así que contemplaba:

- Libertad de comercio e industria. Se reconocía - como garantía social - la libertad de comercio e industria sometida a los requisitos y a las garantías que para su ejercicio prescriban las leyes. Estas podrán establecer o autorizar al gobierno para que fije limitaciones y reservas en el ejercicio de las industrias, cuando así lo imponga la seguridad o necesidad pública, sin que en ningún caso esas restricciones tengan carácter personal ni de confiscación (artículo 45). Pese a establecer la libertad de comercio e industria, el artículo 52 prohibía en lo absoluto el juego de envite (apuesta) en la República. Los locales en que se practique serán clausurados.

- Prohibición de monopolios. Se consideraba como garantía social la prohibición de monopolios. Disponía que se prohíben los monopolios y acaparamientos industriales y comerciales. Las leyes fijarán las penas para los contraventores. Sólo el Estado puede establecer por ley monopolios y estancos en exclusivo interés nacional (artículo 50).

- Constitución de 1933. Las principales reglas de juego relacionadas con la libre competencia fueron:

- Prohibición de monopolios. Se establecía expresamente como garantía nacional y social, que están prohibidos los monopolios y acaparamientos industriales y comerciales. La ley fijará las penas que se impongan a los contraventores. Sólo la ley puede establecer 
Esta revista forma parte del acervo de la Biblioteca Jurídica Virtual del Instituto de Investigaciones Jurídicas de la UNAM

monopolios y estancos del Estado en exclusivo interés nacional (artículo 16).

- Régimen de previsión de las consecuencias económicas. Se estipulaba - como garantía nacional y social - que, en circunstancias extraordinarias de necesidad social, se puede dictar leyes, o autorizar al Poder Ejecutivo para que adopte providencias, tendientes a abaratar las subsistencias. En ninguno de estos casos se expropiarán bienes sin la debida indemnización (artículo 49).

Constitución de 1979. Los principales aspectos regulados en la Constitución de 1979, referente a la libre competencia, fueron:

- Actividad empresarial del Estado. El artículo 113 disponía que el Estado ejerce su actividad empresarial con el fin de promover la economía del país prestar servicios públicos y alcanzar los objetivos de desarrollo. En esa perspectiva, el artículo 114 establecía que por causa de interés social o seguridad nacional la ley puede reservar para el Estado actividades productivas o de servicios. Por iguales causas puede también el Estado establecer reserva de dichas actividades en favor de los peruanos.

- Economía social de mercado. La iniciativa privada es libre. Se ejerce en una economía social de mercado. El Estado estimula y reglamenta su ejercicio para armonizarlo con el interés social (artículo 115). Sin embargo, también se estableció que en situaciones de crisis grave o de emergencia el Estado puede intervenir la actividad económica con medidas transitorias de carácter extraordinario (artículo 132).

- Libertad de comercio e industria. El Estado reconoce la libertad de comercio e industria. La ley determina sus requisitos, garantías, obligaciones y límites. Su ejercicio no puede ser contrario al interés social ni lesivo a la moral, la salud o la seguridad públicas (artículo 131).

- Prohibición de monopolios y oligopolios. El artículo 133 establecía que están prohibidos los monopolios, oligopolios, acaparamientos, prácticas y acuerdos restrictivos en la actividad industrial y mercantil. La ley asegura la normal actividad del mercado y establece las sanciones correspondientes. 
Esta revista forma parte del acervo de la Biblioteca Jurídica Virtual del Instituto de Investigaciones Jurídicas de la UNAM

Por otro lado, el artículo 134 disponía que la prensa, radio televisión y demás medios de expresión y comunicación social y en general las empresas, los bienes y los servicios relacionados con la libertad de expresión y comunicación no pueden ser objeto de exclusividad, monopolio o acaparamiento, directa ni indirectamente, por parte del Estado ni de particulares. Finalmente, el artículo 153 estipulaba que la actividad bancaria financiera y de seguros no puede ser objeto de monopolio privado directa ni indirectamente. La ley señala los requisitos obligaciones garantías y limitaciones de las empresas respectivas. ${ }^{3}$

Por tanto, las constituciones del siglo XX, si bien prohibían el monopolio privado, no establecieron en forma expresa el principio de la libre competencia. No obstante, el artículo 153 de la Constitución de 1979, permitía el monopolio del Estado en el sistema financiero y de seguros, para lo cual disponía que la ley señala los requisitos, obligaciones, garantías y limitaciones de las respectivas empresas.

Asimismo, cabe precisar que, en las constituciones del siglo $\mathrm{XX}$, el principio de la libre competencia estuvo vinculado con otras libertades contempladas igualmente en la Constitución Política, como son la libertad de comercio e industria.

Otro aspecto importante que tomar en cuenta es el artículo 49 de la Constitución de 1933 que facultaba al Poder Ejecutivo para que adopte providencias, tendientes a abaratar las subsistencias, es decir, el Ejecutivo tenía la prerrogativa constitucional para controlar los precios. Dicho artículo si bien fue dejado de lado en la Constitución de 1979, sin embargo, se estableció que en situaciones de crisis grave o de emergencia el Estado podía intervenir la actividad económica con medidas transitorias de carácter extraordinario, lo cual resultó aún más contraproducente.

\section{POSITIVIZACIÓN DEL PRINCIPIO DE LA LIBRE COMPETENCIA EN LA CONSTITUCIÓN ECONÓMICA PERUANA DE 1993}

El principio de la libre competencia fue expresamente consagrado en la Constitución peruana recién en el año 1993, incluyéndose dentro de los

3 Tal como se analiza en el siguiente acápite, ambas constituciones destierran el monopolio privado. Sin embargo, tal como se observa, el artículo 153 de la Constitución de 1979 permitía el monopolio estatal en la actividad bancaria financiera y de seguros, ya que solamente lo prohibía para los privados.

Cuestiones Constitucionales, Núm. 44, Enero-Junio 2021

ISSN: 2448-4881 
Esta revista forma parte del acervo de la Biblioteca Jurídica Virtual del Instituto de Investigaciones Jurídicas de la UNAM

principios generales del régimen económico. Constituye un elemento esencial del modelo económico constitucional peruano. Es así como el primer párrafo del artículo 61 de la Constitución vigente dispone expresamente lo siguiente: "El Estado facilita y vigila la libre competencia. Combate toda práctica que la limite y el abuso de posiciones dominantes o monopólicas. Ninguna ley ni concertación puede autorizar ni establecer monopolios" (Constitución Política del Perú, 1993).

La incorporación del principio de la libre competencia a nivel constitucional permitió adoptar un mecanismo de máxima protección jurídica para asegurar el acceso y actuación en el mercado en igualdad de condiciones, dentro del cual se obtengan ganancias libres, y, sobre todo, que el sistema de precios libres se determine por la interacción de los partícipes en el mercado, y a la vez, lograr el mayor bienestar posible de los consumidores. Por tanto, la protección constitucional de la libre competencia constituye una garantía efectiva para evitar el control de precios en la economía, convirtiéndose en una prohibición ante cualquier intento de intervención de los gobiernos de turno en la economía a través del control de precios. ${ }^{4}$

En efecto, no podría promulgarse una norma que disponga el control de precios de algunos productos, porque devendría en inconstitucional. En la práctica, los gobiernos de turno, sobre todo en la década de los setenta y ochenta, con bastante frecuencia establecieron o bien un precio mínimo, por debajo del cual no se podía vender un producto, o bien un precio máximo, por encima del cual tampoco podía venderse un producto. De igual manera, el gobierno obligaba a través de una norma a realizar una venta a un precio fijo. Por tanto, de presentarse cualquiera de estos casos, tales normas resultarían contrarias al orden constitucional vigente, por vulnerar el principio de la libre competencia, y específicamente, su elemento constitutivo del sistema de precios libres.

De lo establecido en la Constitución, se infiere que el Estado tiene el deber de vigilar la libre competencia y consiguientemente el sistema de

4 Control que ejerce el gobierno sobre los precios de algunos productos, para lo cual se establecen prohibiciones de incrementos o regulaciones para que éstos sean graduales. En la práctica, los controles de precios originan graves problemas, ya que distorsionan la asignación de recursos. Por ejemplo, en Perú a finales de los ochenta, el gobierno de turno estableció controles de precios a diversos alimentos básicos como en pan y la leche, así como también a la gasolina y el dólar (dólar MUC), con la supuesta finalidad de beneficiar a la población; sin embargo, estos controles de precios no obtuvieron el resultado esperado y, por el contrario, generaron escasez e incluso mercados negros. 
Esta revista forma parte del acervo de la Biblioteca Jurídica Virtual del Instituto de Investigaciones Jurídicas de la UNAM

precios libres, como principios económicos orientadores de la actividad económica en el país. Es incuestionable que la libre competencia se fundamenta en la libertad de elegir, dentro de ciertos límites, acerca de los medios y los fines de las actividades de cada individuo.

Sobre el particular, el artículo 61 de la Constitución reconoce la existencia de la libre competencia económica: "la obligación del Estado de facilitarla y de vigilarla, así como... de sancionar los abusos que se consideran a ella contrarios" (Kresalja y Ochoa, 2016: 85). "Es fácil ver que en la medida que el Estado vigila también facilita. Y también es cierto, al contrario: si facilita debe vigilar para que no se cometan excesos con ella (que pueden ser grandes y muy dañinos" (Rubio, 1999: 242).

Esto significa que productores y consumidores concurren al mercado en igualdad de condiciones, de tal manera que los más eficientes tienen la posibilidad de hacer mejores intercambios. Sin embargo, si bien las reglas de juego deben ser claras y debe velarse por su cumplimiento; en algunos casos, se establecen ciertas limitaciones orientadas a proteger el interés público.

Definitivamente, la libre competencia es incompatible con las posiciones dominantes o monopólicas. Por ello, el artículo 61 de la Constitución es bastante claro al disponer que no hay concertación que, pueda autorizar ni establecer monopolios, ni por decisión de personas particulares ni por decisión gubernamental. En efecto, la actual Constitución prohíbe expresamente la creación de monopolios mediante la dación de una ley.

No obstante, en virtud de que la Constitución es una norma integral, resulta necesario precisar que el artículo 72 de la Constitución tipifica una excepción a las reglas de la economía de mercado y libre competencia: "La ley puede, sólo por razón de seguridad nacional, establecer temporalmente restricciones y prohibiciones específicas para la adquisición, posesión, explotación y transferencia de determinados bienes" (Constitución Política del Perú, 1993). Esta disposición es una excepción a las reglas de la economía de mercado y de libre competencia, debido a que dispone que por razón de seguridad nacional se puede establecer restricciones y prohibiciones para la adquisición, posesión, explotación y transferencia de determinados bienes.

Con relación a la constitución europea nadie discute que las normas sobre la competencia, junto a las libertades básicas de circulación constituyen el núcleo fundamental del ordenamiento económico comunitario 
Esta revista forma parte del acervo de la Biblioteca Jurídica Virtual del Instituto de Investigaciones Jurídicas de la UNAM

(García y Maestro, 2006: 147). En efecto, el principio de la libre competencia se encuentra vinculado con otras libertades esenciales contempladas igualmente en la Constitución económica peruana, como son la libre iniciativa privada, ${ }^{5}$ la libertad empresa, comercio e industria, ${ }^{6}$ la libertad de contratar, ${ }^{7}$ la libre producción y comercio exterior, ${ }^{8}$ la libre tenencia de moneda extranjera, ${ }^{9}$ las cuales conjuntamente también orientan el modelo económico del país.

\section{INTERPRETACIÓN DEL PRINCIPIO DE LA LIBRE COMPETENCIA SEGÚN EL TRIBUNAL CONSTITUCIONAL PERUANO}

El principio de la libre competencia ha sido objeto de interpretación por parte del Tribunal Constitucional peruano a través de diversas sentencias. Dentro de este ámbito, la intervención del Estado de justifica para corregir la falla de la competencia. Es así que el Tribunal Constitucional, describe el principio de la libre competencia de la siguiente manera:

El artículo 65 (quiso decir artículo 61) de la Constitución facilita y vigila la libre competencia, y combate toda práctica que la limite; que hay competencia imperfecta en el mercado, cuando el principio constitucional es la libertad de competencia y simultáneamente, en la práctica, existe la concentración de grandes empresas que configuran situaciones de monopolio con alto nivel de competitividad entre ellas; que si bien la posición de dominio en el mercado no está prohibida — porque eso supondría impedir el éxito empresarial— esto es así siempre que dicha posición dominante sea adquirida de manera legítima

5 El artículo 58 de la Constitución dispone expresamente "La iniciativa privada es libre".

6 El artículo 59 de la Constitución dispone expresamente "El Estado estimula la creación de riqueza y garantiza la libertad de trabajo y la libertad de empresa, comercio e industria. El ejercicio de estas libertades no debe ser lesivo a la moral, ni a la salud, ni a la seguridad pública".

7 El artículo 62 de la Constitución dispone expresamente "La libertad de contratar garantiza que las partes pueden pactar válidamente según las normas vigentes al tiempo del contrato. Los términos contractuales no pueden ser modificados por leyes u otras disposiciones de cualquier clase".

8 El artículo 63 de la Constitución dispone expresamente "La producción de bienes y servicios y el comercio exterior son libres".

9 El artículo 64 de la Constitución dispone expresamente "El Estado garantiza la libre tenencia y disposición de moneda extranjera”. 
Esta revista forma parte del acervo de la Biblioteca Jurídica Virtual del Instituto de Investigaciones Jurídicas de la UNAM

y no en base a normas jurídicas que sin justificación razonable la privilegian, vulnerando el principio de igualdad ante la ley, por lo que no es aceptable que el Decreto Supremo Núm. 158-99-EF establezca una clasificación arbitraria, que otorga un trato preferencial a una categoría de cigarrillos, favoreciendo a algunos productores y/o comercializadores, respecto a los demás (Tribunal Constitucional [Perú], EXP. Núm. 1311-2000-AA, F.J. 4).

Como puede apreciarse, el Tribunal Constitucional considera que la posición de dominio en el mercado no está prohibida por sí misma, lo que se prohíbe es el abuso de la posición dominante o aquellas prácticas que estén orientadas de manera exclusiva a restringir la competencia, como la concertación de precios. En efecto, podría presentarse una situación inicial en la que existen varias empresas que compiten en el mercado, sin embargo, algunas de éstas pueden tener una mayor cuota de mercado, con lo cual tienen una posición de dominio. Esta situación no es la que se castiga, lo que se prohíbe son los abusos que podrían devenir a causa de dicha posición de dominio.

En una sentencia posterior, el Tribunal Constitucional, realizó precisiones al principio de la libre competencia:

33. De lo expuesto, se desprende que la libre iniciativa privada y, concomitantemente, la libre competencia y demás libertades patrimoniales consagradas en la Constitución y ejercitadas en el seno del mercado, presuponen necesariamente tres requisitos:

a) La autodeterminación de iniciativas o de acceso empresarial a la actividad económica;

b) La autodeterminación para elegir las circunstancias, modo y forma de ejercitar la actividad económica; $y$,

c) La igualdad de los competidores ante la ley.

A estos requisitos que determinan conjuntamente las garantías de defensa de los intereses individuales en la economía, se suman aquellos que garantizan el interés comunitario; a saber:

a) La sujeción a la Constitución y a las leyes;

b) El respeto de los derechos fundamentales; $y$,

c) La proyección de cualquier actividad económica hacia el bien común.

El ejercicio de toda actividad económica puede limitarse. Sin embargo, es preciso que las restricciones legales adoptadas no enerven esa legítima autonomía, así como también impidan a los operadores económicos pri- 
Esta revista forma parte del acervo de la Biblioteca Jurídica Virtual del Instituto de Investigaciones Jurídicas de la UNAM

vados diseñar su propia estrategia para ofrecer, adquirir, vender o hasta permutar en el mercado. Ello, sin perjuicio de reconocer que incluso las medidas estatales que pretendan operar sobre el ámbito de las libertades económicas deben ser razonables y proporcionadas.

37. Asimismo, el artículo 61 confiere al Estado el deber de proscribir y combatir toda práctica que limite la libre competencia, así como el abuso de las posiciones dominantes o monopólicas. De esta forma, nuestro texto fundamental no admite que un solo productor satisfaga la demanda de todos los consumidores o usuarios, pues ello, en los hechos, le permitiría determinar el precio y la cantidad de bienes o servicios a ofertarse, a costa de extraer recursos del consumidor o usuario.

El Estado debe, asimismo, evitar la instauración de posiciones dominantes, esto es, la existencia de escenarios económicos en los que aparezca un agente con capacidad de actuación independiente, es decir, con opción de prescindencia de sus competidores, compradores y clientes o proveedores en función a factores tales como la participación significativa de las empresas en los mercados respectivos, las peculiares características de la oferta y la demanda de los bienes o servicios, el desarrollo tecnológico, etcétera.

En coherencia con tales imperativos se justifica la existencia de una legislación antimonopólica y de desarrollo de los marcos regulatorios que permitan mayores niveles de competencia.

50. Debe tenerse en cuenta, asimismo, el papel de los precios de los bienes y los servicios, y su importancia decisiva para el adecuado desenvolvimiento del mercado.

En circunstancias comunes, el precio no es sino el resultado de las decisiones racionales adoptadas por ofertantes y usuarios. Cuando su fijación no es artificial, sino estricta consecuencia del intercambio fluido de bienes y servicios, el precio brinda información valiosa a los agentes económicos, tanto en lo que respecta a la escasez relativa de los recursos, como a las condiciones de la oferta y la demanda.

Del mismo modo, la información contenida en la fijación del precio en un mercado libre incentiva a las empresas a aumentar su eficiencia, a reducir sus costos y a mejorar la calidad de los productos que ofrece, en beneficio de los usuarios y consumidores. (Tribunal Constitucional [Perú], EXP. Núm. 0008-2003-AI/TC, F.J. 33, 37 y 50).

En este expediente, el Tribunal Constitucional alude de manera expresa a requisitos de la libre iniciativa privada, la libre competencia y las libertades patrimoniales (fundamento jurídico 33); es así que, con relación a 
Esta revista forma parte del acervo de la Biblioteca Jurídica Virtual del Instituto de Investigaciones Jurídicas de la UNAM

los requisitos, la sentencia bajo análisis, incorpora tres elementos constitutivos del principio constitucional de la libre competencia, los mismos que se enmarcan por el lado de la oferta, denominándolos garantías de defensa de los intereses individuales en la economía y son: el acceso empresarial a la actividad económica, la libertad de elegir la actividad económica y la igualdad de los competidores ante la ley. También, añade otros tres requisitos que garantizan el interés comunitario: a) la sujeción a la Constitución y a las leyes, b) el respeto de los derechos fundamentales; $\mathrm{y}, c$ ) la proyección de cualquier actividad económica hacia el bien común.

De igual forma, de acuerdo con el Tribunal Constitucional, el Estado debe combatir toda práctica que limite la libre competencia, así como el abuso de posiciones dominantes o monopólicas, las cuales también limitan o pueden limitar la libre competencia. No obstante, el artículo 61 de la Constitución es bastante claro al no prohibir que un agente alcance una posición de dominio en el mercado. Lo que sí censura, es el abuso y, por ello, ordena al poder público combatirla eficazmente, con la finalidad de garantizar la libre participación de empresas por el lado de la oferta y de los consumidores por el lado de la demanda (fundamento jurídico 37 ).

Desde luego, el abuso de una posición de dominio o de una posición monopólica, significa aprovecharse de esa condición, contraviniendo las reglas de la libre competencia. Esto implica que la empresa con alguna ventaja en el mercado realiza actos orientados a restringir, afectar o distorsionar la competencia de manera significativa.

A su vez, en el fundamento jurídico 50 del expediente en cuestión, el Tribunal Constitucional prescribe la importancia decisiva del papel de los precios para el adecuado desenvolvimiento del mercado, precisando que cuando su fijación no es artificial, sino estricta consecuencia del intercambio fluido de bienes y servicios, el precio brinda información valiosa a los agentes económicos, tanto en lo que respecta a la escasez relativa de los recursos, como a las condiciones de la oferta y la demanda; y que la información contenida en la fijación del precio en un mercado libre incentiva a las empresas a aumentar su eficiencia, a reducir sus costos y a mejorar la calidad de los productos que ofrece, en beneficio de los usuarios y consumidores. Sin embargo, todas estas precisiones referidas al rol de los precios en la economía, desde la óptica del Tribunal Constitucional no son elementos constitutivos del principio de la libre competencia. 
Esta revista forma parte del acervo de la Biblioteca Jurídica Virtual del Instituto de Investigaciones Jurídicas de la UNAM

El Estado puede intervenir a favor de la persona en virtud de que no tiene cabida la autorregulación del mercado.

La presencia activa del Estado es indispensable para intervenir - sin detrimento de la libertad - a favor de la persona, de sus derechos, de la igualdad de oportunidades y de trato, del desarrollo, de la solidaridad, y del sistema axiológico de la Constitución no puede tener cabida una autorregulación del mercado autosuficiente en su libre competencia irrestricta por el juego espontáneo de la oferta y la demanda, aunque sólo sea en razón de que la dignidad del ser humano y sus derechos fundamentales no son objetos que entren ni deban entrar al mercado. (Bidart, 2002, p. 6).

De ahí que para que funcione el mercado de manera más eficiente posible, resulta necesario que el Estado cree un sistema jurídico-institucional adecuado para promover la competencia, sin constreñir la libertad de elegir de los que participan en un intercambio. Por tanto, la competencia debe ser el objetivo prioritario y la regulación el instrumento o medio necesario para preservar la competencia.

De la misma manera, existe otra sentencia en la que el Tribunal Constitucional, también desarrolla el contenido del principio de la libre competencia:

El concepto de libre competencia al que apunta la Constitución Política del Perú se adscribe al cuadro más amplio de la libertad económica. Como tal supone dos aspectos esenciales:

a) La libertad de acceso al mercado por parte de los diversos agentes económicos. Desde la primera perspectiva, queda claro que quien tiene la capacidad de producir un bien o prestar un servicio, debe acceder al mercado en condiciones autodeterminativas, esto es, sin que nadie (ni el Estado ni el resto de los agentes económicos) pueda impedir o restringir dicha participación.

b) La libertad de iniciativa o actuación dentro del mercado. Es evidente que tras haberse accedido al mercado, se debe gozar de la suficiente capacidad de autodeterminación para competir conforme a las propias condiciones y variables económicas impuestas por la llamada ley de la oferta y la demanda (Tribunal Constitucional [Perú], EXP. Núm. 3315-2004-AA/ TC, F.J. 16). 
Esta revista forma parte del acervo de la Biblioteca Jurídica Virtual del Instituto de Investigaciones Jurídicas de la UNAM

En definitiva, la libre competencia es un principio esencial del régimen económico constitucional peruano, a través del cual se garantiza la concurrencia de una pluralidad de agentes económicos en el mercado, sean estos ofertantes o demandantes. Esto quiere decir que el Tribunal Constitucional enfoca la libre competencia por el lado de la oferta y la demanda.

Igualmente, en otras dos sentencias, el Tribunal Constitucional, al referirse al contenido del principio de la libre competencia, incorpora el hecho de garantizar el acceso al mercado en igualdad de condiciones, haciendo énfasis en los ofertantes y demandantes:

Finalmente, como aspecto fundamental de una economía social de mercado, el Estado facilita y vigila la libre competencia. El artículo 61 de la Constitución delega al legislador la labor de garantizar el acceso al mercado en igualdad de condiciones, al tiempo de reprimir y limitar el abuso de posiciones de dominio o monopólicas a efectos de garantizar no sólo la participación de los agentes de mercado ofertantes, sino de proteger a quienes cierran el circulo económico en calidad de consumidores y usuarios. (Tribunal Constitucional [Perú], EXP. Núm. 00034-2004-PI-TC, F.J. 32, y EXP. Núm. 0019-2006-PI/ TC, F.J. 27).

Asimismo, el Tribunal Constitucional, define el principio de la libre competencia y dispone sus requisitos:

18. El artículo 61 de la Constitución prescribe que "El estado facilita y vigila la libre competencia". Se le puede definir como la potestad de coexistencia de una pluralidad de ofertas en el campo de la producción, servicios o comercialización de productos de la misma especie por parte de un número indeterminado de agentes económicos.

19. Esta facultad económica plantea el libre juego de la oferta y la demanda, y presupone la presencia de los tres requisitos siguientes (STC 0018-2003-AI/TC).

a. La autodeterminación de iniciativas o de acceso empresarial a la actividad económica.

b. La autodeterminación para elegir las circunstancias, modos y formas de ejecutar la actividad económica (calidad, modelo, volumen de producción, etcétera).

c. La igualdad de los competidores ante la ley. (Tribunal Constitucional [Perú], EXP. Núm. 01405-2010-PA/TC, F.J. 18 y 19). 
Esta revista forma parte del acervo de la Biblioteca Jurídica Virtual del Instituto de Investigaciones Jurídicas de la UNAM

Esta sentencia recoge todo lo señalado en una anterior sentencia (Tribunal Constitucional [Perú], EXP. Núm. 0018-2003-AI/TC), tanto la definición como los requisitos. Al respecto, cabe precisar que, si bien se plantea libre competencia como el libre juego de la oferta y la demanda, al momento de establecer sus requisitos, éstos se conciben únicamente desde el lado de la oferta.

De igual manera, el Tribunal Constitucional, define el alcance del rol del Estado respecto de facilitar y vigilar la libre competencia.

La libre competencia consagrada en el artículo 61 de la Constitución, cuyo texto prescribe que "El Estado facilita y vigila la libre competencia (...)", se define como la potestad de coexistencia de una pluralidad de ofertas en el campo de la producción, servicios o comercialización de productos de la misma especie por parte de un número indeterminado de agentes económicos. Esta facultad económica plantea el libre juego de la oferta y la demanda, y presupone la presencia de los tres requisitos siguientes: a) la autodeterminación de iniciativas o de acceso empresarial a la actividad económica; $b$ ) la autodeterminación para elegir las circunstancias, modos y formas de ejecutar la actividad económica (calidad, modelo, volumen de producción, etcétera); y c) la igualdad de los competidores ante la ley (la no discriminación). (Tribunal Constitucional [Perú], EXP. Núm. 03479-2011-PA/TC, F.J. 7).

Aquí, la referida sentencia alude a la libre competencia como facultad económica que presupone tres requisitos para su configuración: acceso a la actividad económica de manera libre, libertad de elegir las formas de realizar una actividad económica e igualdad de los competidores ante la ley.

De las sentencias analizadas se pudo evidenciar que el Tribunal Constitucional no ha contemplado como parte de los elementos constitutivos del principio constitucional de la libre competencia el sistema de precios y las ganancias libres en el mercado.

\section{FALLA DE LA COMPETENCIA, PODER DE MERCADO Y PROTECCIÓN LEGAL DE LA LIBRE COMPETENCIA}

La libre competencia "subyace a la política económica" (Blanco, 2019, p. 292). En efecto, la protección legal de la libre competencia constituye un elemento fundamental del modelo económico peruano, y sirve de criterio orientador de la política económica de los gobiernos de turno. 
Esta revista forma parte del acervo de la Biblioteca Jurídica Virtual del Instituto de Investigaciones Jurídicas de la UNAM

Una de las razones básicas que justifica la intervención del Estado en la economía es la ineficiencia económica originada por diversas fallas del mercado: externalidades, mercados incompletos, falla de la competencia, existencia de bienes públicos, asimetrías de la información, déficit presupuestario, desempleo e inflación. Dentro de este ámbito, la falla de la competencia se presenta porque existe un número reducido de partícipes en el mercado, lo que comúnmente se conoce como competencia imperfecta, la cual se asocia a cualquiera de los tipos de imperfección del mercado: competencia monopolística, monopolio, monopsonio, oligopolio, oligopsonio. De manera que, la falla de la competencia justifica la intervención del Estado para que éste corrija cualquier situación que la obstaculice.

Contrario a ello, los mercados competitivos se caracterizan porque las empresas venden un producto estandarizado u homogéneo (características idénticas), todos los participantes del mercado son precio-aceptantes (ofertantes y demandantes son tomadores de precios, por lo que ninguno puede influir en el precio de mercado), los agentes tienen información perfecta (información simétrica), existe libertad de entrada y salida del mercado y no hay externalidades.

Si bien lo ideal es que los mercados sean competitivos, la realidad está más vinculada a la competencia imperfecta, esto es, una estructura mercado en la cual, por lo menos un productor o vendedor por el lado de la oferta, o también, por lo menos un comprador por el lado de la demanda es lo suficientemente grande como para influir en el precio de un bien. Al respecto, cabe señalar que:

El monopolio, concebido como situación de hecho y no como limitación social de la libre competencia, es lo más antiguo y primigenio, mientras que la competencia surge sólo en una etapa posterior, la misma que se desarrolla con el progreso de la cultura económica (Menger, 2013: 278).

Dentro de este marco, "la habilidad de un monopolista para elevar su precio por encima del nivel competitivo mediante la reducción del volumen de producción se denomina poder de mercado" (Krugman y Wells, 2013: 376).

Desde tal perspectiva, la protección legal de la libre competencia por parte del Estado surge a partir de los incentivos que tienen las empresas ante una situación de aprovecharse de las ventajas del mismo mercado. 
Esta revista forma parte del acervo de la Biblioteca Jurídica Virtual del Instituto de Investigaciones Jurídicas de la UNAM

La protección de la libre competencia es un propósito fundamental en el cual los Estados modernos han progresado desde la aparición de la teoría económica neoclásica (finales del siglo XIX) y de la eclosión de grandes monopolios en sectores sensibles como el ferroviario, el del acero y el de los hidrocarburos (Soto, 2019: 78).

En ese sentido, las políticas antimonopolio se diseñan por los gobiernos de turno para facilitar y vigilar la competencia en el mercado a través de la limitación del dominio de mercado, así como de prácticas restrictivas (relaciones entre las empresas y sus distribuidores y proveedores que incluyen contratos de venta exclusiva y discriminación de precios). De este modo:

Las empresas tienen incentivos perversos para obtener poder sobre el mercado, o sea, para lograr un control discrecional sobre los precios y otros factores asociados. Este poder puede surgir limitando la competencia por medio de la imposición de barreras al comercio y/o legalización de arreglos colusorios para restringir los precios y la productividad y otras prácticas que generalmente se consideran como un fracaso del mercado, ocasionando una asignación ineficiente de recursos y afectando adversamente el rendimiento de la industria y el bienestar socioeconómico (Alarcón, 2016: 119).

Dicha realidad es la que justifica la regulación para promover e incentivar la competencia en el mercado, con el fin de evitar ineficiencias e inequidades que afectan directamente el bienestar de los agentes que intervienen en cualquier sector de la economía.

El funcionamiento de la competencia no sólo exige una adecuada organización de ciertas instituciones como el dinero, los mercados y los canales de información, sino que depende, sobre todo, de la existencia de un sistema legal apropiado, orientado a preservar la competencia y a lograr que ésta opere de la manera más beneficiosa posible (Hayek, 2011: 87).

De ahí que la defensa de la competencia implica la intervención del aparato estatal a través de la regulación, con el objeto de establecer mecanismos antimonopólicos para controlar el ejercicio del poder de mercado. En efecto, "La primera fuente de la falla del mercado es el monopolio en sus diversas formas: monopolio en el mercado de productos, colusión entre 
Esta revista forma parte del acervo de la Biblioteca Jurídica Virtual del Instituto de Investigaciones Jurídicas de la UNAM

empresas o proveedores de insumos y monopsonio" (Cooter y Ulen, 1998: $61)$.

Como refieren Posner, Landes y Kelman (2011: 81), “el principal objeto del derecho de la competencia es el control de los monopolios y el estudio de los monopolios ha sido una de las principales actividades de los economistas durante muchos años".

El derecho de la competencia supone tres planteamientos diferentes para reducir los costos asociados a los monopolios: controlar su formación (mediante restricciones a las fusiones de grandes empresas, limitaciones a las políticas de precios agresivas a través de la venta de productos por debajo del costo para expulsar a los competidores del mercado y obstaculizaciones a la cooperación de empresas en sectores concentrados), su regulación y los esfuerzos por sacar provecho indebido de un monopolio legal (Friedman, 2015).

Por otro lado, "las conductas contrarias a la competencia son: conductas concertadas entre competidores para no competir (colusión), conductas que intentan excluir competidores reales o potenciales, y conductas abusivas que implican el ejercicio directo del poder de mercado en perjuicio de los consumidores" (Coloma, 2001: 260). Por ello, desde el Estado, existe la necesidad de reprimir, neutralizar y sancionar las conductas identificadas como anticompetitivas. De igual forma, la represión de la competencia desleal busca que el proceso competitivo natural (lucro) no se vea afectado.

Siendo así, el sistema legal resulta importante para la preservación de la competencia, pero no para obstruirla ni obstaculizarla, sino por el contrario, para hacer que ésta fluya y permita generar el mayor beneficio posible a los que participan en dicho proceso de descubrimiento. Por lo tanto, el gobierno debe promover la competencia, impidiendo aquellas prácticas que restrinjan la libre competencia, así como la competencia desleal. En esa orientación, la finalidad de la represión de conductas anticompetitivas es velar por el bienestar del mercado y con ello el del consumidor.

Por último, "algunas imperfecciones de la competencia se deben a la intervención del Estado. Éste concede patentes a los innovadores. Aunque las patentes son importantes para dar incentivos a la innovación, hacen que la competencia en el mercado no sea perfecta" (Stiglitz y Rosengard, 2015: 127). "Pues, aunque es cierto que el primer descubridor se beneficia del privilegio, también lo es que sus competidores quedan excluidos de la 
Esta revista forma parte del acervo de la Biblioteca Jurídica Virtual del Instituto de Investigaciones Jurídicas de la UNAM

producción en el área de la patente por muchos años" (Rothbard, 2015: 89). Estas fallas de la regulación tienden a generar los siguientes problemas: captura del regulador; asimetría de información entre el Estado y el sector privado; beneficios concentrados en un grupo de personas; gestión de intereses en el aparato estatal ante políticos o funcionarios; corrupción de los funcionarios públicos.

\section{CONCLUSIONES}

El principio de la libre competencia no estaba previsto expresamente en la Constitución de 1979, su incorporacion recién se dio con la Constitución de 1993, en un contexto de reforma estatal influenciado por la crisis económica que atravesó el Perú a finales de los ochenta e inicio de los noventa.

Desde la perspectiva de la Constitución económica, el principio de la libre competencia constituye uno de los principios esenciales consagrados en la Constitución Política de Perú que orienta el modelo económico del país. Como tal, impone un mandato orientado a garantizar el intercambio eficiente en el mercado, a tal punto de defender la competencia y sancionar los abusos. La gran ventaja que tiene la preservación de la competencia por el lado de la oferta es que eleva el bienestar de los consumidores. Para tal efecto, se requiere contar con un gobierno limitado, que respete la libertad de elegir de los individuos, y a la vez, facilite y vigile la libre competencia.

La libre competencia es el mecanismo más efectivo para fomentar la asignación eficiente de los recursos en el mercado, sus elementos constitutivos son acceso libre al mercado, actuación libre en el intercambio, sistema de precios libres, ganancias libres e igualdad de los competidores ante la ley. Claramente la protección constitucional de la libre competencia implica garantizar un sistema de precios libres y la obtención de ganancias libres en el mercado, elementos constitutivos trascedentes que no han sido considerados en la interpretación del Tribunal Constitucional peruano.

La verdadera función del sistema de precios es considerar dicho sistema como un mecanismo que permite comunicar información entre los ofertantes y demandantes. Un aspecto importante que se debe resaltar es que el principio de la libre competencia conlleva implícitamente la prohibición del control de precios, con lo cual, la protección constitucional de la libre 
Esta revista forma parte del acervo de la Biblioteca Jurídica Virtual del Instituto de Investigaciones Jurídicas de la UNAM

competencia constituye un mecanismo efectivo para evitar el control de precios de los bienes y servicios.

Es indudable que en el proceso de descubrimiento de la competencia se presenta una serie de situaciones, y sobre todo regulaciones por parte del Estado, que terminan dosificando o desvirtuando el libre ejercicio de la competencia, tanto por el lado de las empresas como por el lado de los consumidores.

El incentivo que tienen las empresas para obtener un mayor poder en el mercado, que puede surgir por medio de la imposición de barreras al comercio, así como de prácticas colusorias entre otras formas, es lo que justifica la intervención del Estado a través de la regulación con el objeto de fomentar la competencia en el mercado, para así evitar ineficiencias que afecten el bienestar de los agentes que participan en un mercado.

En suma, el Estado debe preservar la libre competencia, para promover el intercambio más eficiente en el mercado. No obstante, un eficaz sistema de libre competencia requiere una estructura legal sólida que establezca principios constitucionales y normas de menor jerarquía, de tal forma que éstas últimas puedan ser ajustadas continuamente para lograr el buen funcionamiento de los diversos mercados.

\section{FUENTES CONSULTADAS}

Alarcón, A. (2016). La libre competencia económica en el derecho colombiano: una revisión desde la economía social de mercado y sus implicaciones normativas. Revista Prolegómenos Derechos y Valores, 19(37), 109-124. Disponible en: http://dx.doi.org/10.18359/prole.1683.

BIDART, G. (2002). La constitución económica (un esbozo desde el derecho constitucional argentino). Cuestiones Constitucionales. Revista Mexicana de Derecho Constitucional, Núm. 6, 3-16. Disponible en: http://dx.doi.org/10.22201/iij.24484881e.2002.6.5636.

Blanco, C., y CoRredor, J. (2019). Estándares internacionales de regulación financiera y Estado social de derecho en Colombia, Cuestiones Constitucionales. Revista Mexicana de Derecho Constitucional, Núm. 41. Disponible en: http://dx.doi.org/10.22201/ iij.24484881e.2019.41.13948. 
Esta revista forma parte del acervo de la Biblioteca Jurídica Virtual del Instituto de Investigaciones Jurídicas de la UNAM

Boloña, C. (1995). Cambio de rumbo. Lima: Instituto de Economía de Libre Mercado.

Chanamé, R. (2009). Comentarios a la Constitución. Lima: Jurista Editores E.I.R.L.

COASE, R. (1988). La empresa el mercado y la ley. España: Alianza Editorial.

Constitución Política del Perú 1993, Congreso Constituyente Democrático, Diario Oficial El Peruano (29 de diciembre de 1993).

Coloma, G. (2001). Análisis económico del derecho privado y regulatorio. Argentina: Editorial de Ciencia y Cultura.

Cooter, R., y Ulen, T. (1998). Derecho y Economía. México: Fondo de Cultura Económica.

FrIEDMAN, D. (2015). El orden del derecho. Madrid: Editorial INNISFREE.

FriedmAn, M., y FriedMAN, R. (1980). Libertad de elegir. España: Ediciones Grijalbo S.A.

García, M. A., y MAESTRO, G. (2006). Dirección económica y mercado en la Constitución europea. Cuestiones Constitucionales. Revista Mexicana de Derecho Constitucional, Núm. 15, 137-175. Disponible en: http://dx.doi.org/10.22201/iij.24484881e.2006.15.5773.

HAYEK, F. A. (2011). Camino de servidumbre. (3a. ed.). España: Alianza Editorial.

HAYeK, F. A. (2014). Derecho, legislación y libertad. (2a ed.). España: Unión Editorial S.A.

HAYEK, F. A. (2015). Nuevos estudios de filosofía, politica, economía e historia de las ideas. (2a. ed.) España: Unión Editorial S. A.

KIRZNER, I. M. (1998). Competencia y empresarialidad. (2a ed.). España: Alianza Editorial.

Kresalja, B., y OchoA, C. (2016). Derecho constitucional económico, Lima: Fondo Editorial Pontificia Universidad Católica del Perú.

Krugman, P., y WeLls, R. (2013). Microeconomía. (3a. ed.). Barcelona: Editorial Reverté S. A.

Menger, C. (2013). Principios de economía política. (2a. ed.). España: Unión Editorial S. A. 
Esta revista forma parte del acervo de la Biblioteca Jurídica Virtual del Instituto de Investigaciones Jurídicas de la UNAM

MiseS, L. (2011). La acción humana. (10a. ed.). España: Unión Editorial S. A.

Posner, R., LANDes, W., y Kelman, M. (2011). Análisis económico del derecho. Colombia: Panamericana Formas e Impresos S. A.

ROTHBARD, M. (2013). El hombre, la economía y el Estado, Tratado sobre principios de Economía. (volumen II). España: Unión Editorial S. A.

Rothbard, M. (2015). Poder y mercado. El gobierno y la economía. Guatemala: Unión Editorial S. A.

Rubio, M. (1999). Estudio de la Constitución Política de 1993. (tomo III). Lima: Fondo Editorial PUCP.

Rubio, M. (2013). La interpretación de la Constitución según el Tribunal Constitucional. (3a. ed.) Lima: Fondo Editorial PUCP.

Smith, A. (2011). Riqueza de las naciones. (3a ed.). España: Alianza Editorial S. A.

Soto, J. A., y JARAMiLlo DE los Ríos, L. F. (2019). Aspectos comunes de las escuelas de Chicago y Harvard en materia de libre competencia: el aporte del neoinstitucionalismo, Boletín Mexicano de Derecho Comparado, 51(154), 77-106. Disponible en: http://dx.doi.org/10.22201/ iij.24484873e.2019.154.14138.

STIGLitZ, J. E., y RosengARD, J. K. (2015). La economía del sector público. (4a. ed.) España: Antoni Bosch, editor S. A.

TASSANO, H. (2016). Competencia y regulación. Derecho PUCP, (76), $105-$ 121. Disponible en: https://doi.org/10.18800/derechopucp.201601.004.

Tribunal Constitucional [Perú], EXP. Núm. 1311-2000-AA (Tribunal Constitucional, 19 de junio de 2001). Disponible en: https://www. tc.gob.pe/jurisprudencia/2001/01311-2000-AA.html.

Tribunal Constitucional [Perú], EXP. Núm. 0008-2003-AI/TC (Tribunal Constitucional, 11 de noviembre de 2003). Disponible en: https://www. tc.gob.pe/jurisprudencia/2003/00008-2003-AI.html.

Tribunal Constitucional [Perú], EXP. Núm. 0018-2003-AI/TC (Tribunal Constitucional, 26 de abril de 2004). Disponible en: https:/tc.gob.pe/ jurisprudencia/2004/00018-2003-AI.html.

Tribunal Constitucional [Perú], EXP. Núm. 00034-2004-PI-TC (Tribunal Constitucional, 15 de febrero de 2005). Disponible en: https://tc.gob. pe/jurisprudencia/2006/00034-2004-AI.pdf. 
Esta revista forma parte del acervo de la Biblioteca Jurídica Virtual del Instituto de Investigaciones Jurídicas de la UNAM

Tribunal Constitucional [Perú], EXP. Núm. 3315-2004-AA/TC (Tribunal Constitucional, 17 de enero de 2005). Disponible en: https://www. tc.gob.pe/jurisprudencia/2005/03315-2004-AA.html.

Tribunal Constitucional [Perú], EXP. Núm. 0019-2006-PI/TC (Tribunal Constitucional, 14 de marzo de 2007). Disponible en: https://tc.gob.pe/ jurisprudencia/2007/00019-2006-AI.pdf.

Tribunal Constitucional [Perú], EXP. Núm. 01405-2010-PA/TC (Tribunal Constitucional, 6 de diciembre de 2010). Disponible en: https://www. tc.gob.pe/jurisprudencia/2011/01405-2010-AA.html.

Tribunal Constitucional [Perú], EXP. Núm. 03479-2011-PA/TC (Tribunal Constitucional, 30 de abril de 2014). Disponible en: https://www.tc.gob. pe/jurisprudencia/2014/03479-2011-AA.html. 